\title{
The Effect of Information Asymmetry on Consumer Driven Health Plans
}

\author{
Martin J. D'Cruz ${ }^{1}$ \& Ranjan B. Kini ${ }^{2}$ \\ ${ }^{\mathrm{I}}$ Turku School of Economics, Turku, Finland \\ ${ }^{2}$ School of Business, Indiana University Northwest, Gary, IN, US
}

\begin{abstract}
The healthcare industry is unique when compared to other industries in that multiple stakeholders manage healthcare services. Consumers are the ultimate users of these services; however, they have relatively little influence on their own health service choices. The industry is changing rapidly with new technologies making access to healthcare information via the Internet and other sources easier in theory. The disconnect between what consumers can learn and their ability to use what they learn results in the inability for them to truly be drivers in their own healthcare decisions. Information Asymmetry is one of the major factors that make the healthcare delivery system in the United States and other countries inefficient. The stakeholders, government, health plans, providers and employers play a pivotal role in reducing information asymmetry. Embracing Information and Communications Technology (ICT) can effectively move from an unwired to a wired healthcare delivery system and support reducing information asymmetry. For Consumer Driven Health Plans (CDHP) to succeed, consumers need information on price, quality, and cost for services. The conjecture here is that with minimization of information asymmetry, implicitly or explicitly, CDHP will drive healthcare cost down and make the healthcare market more efficient thereby reining in healthcare cost in the long-run.
\end{abstract}

\section{Introduction}

The health care industry is unique when compared to other industries in that healthcare services are managed by government, health plans, providers, and employers. Consumers are the ultimate users of these healthcare services; however, consumers today have relatively little influence on their own health service choices. The industry is changing rapidly with new technologies, making access to health care information via the Internet and other sources easier in theory. The disconnect between what consumers can learn and how they can use what they learn, results in this inability for them to truly be the drivers in their own health care decisions. It is believed that existence of such asymmetry in the availability of information to the consumers and other stakeholders, understood as Information Asymmetry, is one of the major factors that makes healthcare delivery in the United States (and perhaps the world)

Please use the following format when citing this chapter:

D'Cruz, M., J., Kini, R. B., 2007, in IFIP International Federation for Information Processing, Volume 251, Integration and Innovation (Orient to F.-Society Volumel, Wang, W. (Fds), (Boston: Springer), pp. 353-362. 
inefficient. It is also generally believed that leveraging Information and Communication Technology (ICT) can effectively address this factor from an unwired to wired healthcare delivery system [1].

In this paper, a discussion of the effects of information asymmetry on CDHP products is presented. The stakeholders of this eco-system are the Government, Employers, Health Plans, Providers (hospitals and physicians), and Consumers. The discussion will identify and present the role of information asymmetry as a contributing factor to healthcare industry inefficiencies. Further, the discussion will also include the trend in the shift of health care cost to consumers with the growth of Consumer Driven Health Plans in Managed Care. The critical role of Information and Communication Technology in minimizing information asymmetry in health care industry and its influence in gaining efficiencies in health care is also presented.

\section{Research}

The effect of Information Asymmetry is considered one of the major factors in stifling the growth of CDHPs. Information asymmetry is defined as unequal information and the consequent role of physicians as agents for patients. It is a situation in which a few have relevant information, and the rest have little. Information asymmetry causes markets to become inefficient since not all the participants have access to the information they need for their decision-making processes. Information asymmetry is defined as a gap in knowledge between consumers and professionals regarding price and quality. This gap of interpreting performance metrics of physicians, providers and health plans can be difficult when one party to a transaction has more or better information than the other party [2].

The stakeholders, the Government, Employers, Providers, Health Plans and Consumers recognize that healthcare cost is out of control and cannot be sustainable in the long run. Healthcare professionals and policy makers discuss healthcare information and strategies, but few suggest ideas to fix the problem. Managed Care is now considered a fad that has Plans (CDHP) costs shift to the consumer. There are already concerns regarding consumer's satisfaction with these plans, and the future is less than perfectly clear.

Consumer Driven Health Plans

To understand how Consumer Driven Health Plan (CDHP) concept was born, it helps to understand how the U.S. healthcare system has evolved over the past 50 years. For, in that evolution are lessons the society has learned with respect to healthcare consumption, management and costs. Employer-sponsored benefits were born in the 1950 s as a way for employers to attract and retain employees, and that premise holds through today. However, as American businesses continue to reel in the slumping economy of the new Millennium, how to manage what appears to be an endless cycle of dramatic healthcare cost increases, and, questioning the continuation of funding healthcare benefits moreover, is a business issue that employers large and small are taking on with a new vigor.

There has been a consensus among the stakeholders that something needs to done to reign the costs of healthcare. This involved getting consumers more engaged in the healthcare decision making process. There was consensus that healthcare costs were rising dramatically, and unlike the at-hand solutions that 
managed care provided in the $1980 \mathrm{~s}$ and $1990 \mathrm{~s}$, there was only one viable solution to manage the new cost trends: Engage the consumer in the purchasing, pricing and utilization of their healthcare services. Defined narrowly, CDHP refers to health insurance plans that allow members to use personal Health Savings Accounts (HSAs), Health Reimbursement Arrangements (HRAs), or similar medical payment products to pay medical expenses directly, while they enjoy the protection of a high-deductible health insurance policy. Highdeductible policies cost less per month than low-deductible policies, but the consumer needs to pay more upfront for medical procedures. This system of healthcare is also often referred to as "consumer directed health care" because proponents believe it gives consumers greater control over their health and health care costs.

Cardon and Showalter article identifies five main types of tax-preferred health savings accounts shown below [3]:

1. Archer Medical Savings Accounts (MSAs): accounts in which an individual and/or an employer can contribute pre-tax dollars to pay for most health care services. The tax advantage is the same as for employer-provided health insurance premiums. Unused monies can accumulate over time. An experiment authorized under the Kassebaum-Kennedy bill (Health Insurance Portability and Accountability Act of 1996) allowed for restricted introduction of MSAs which included the requirement of purchasing a catastrophic, (high-deductible) health insurance policy.

2. Flexible Spending Accounts (FSAs): like HSAs, but with no link to insurance coverage. Funds not used by the end of the year revert to the employer. 3. Rollover FSAs: these would allow limited rollover of FSA monies without the restrictions on insurance choices that the current HSA rules require.

4. Health Reimbursement Arrangements (HRAs): tax-exempt individual accounts used to pay for medical expenditures. Employers fund accounts; employee contributions are not allowed. Ownership of the accounts remains with the employer, unlike HSAs and FSAs.

5. Medical IRAs. This proposal would allow consumers to make penalty-free early withdrawals from their retirement plans to pay for allowable medical expenditures.

Proponents argue that most consumers will pay less for healthcare in the long run under CDHP because not only their monthly premiums will be lower, but also the use of HSAs and similar products will bring back free-market variables into the healthcare system that will encourage competition, lower prices, improved services and lower medical errors.

In its infancy stages, CDHP is manifesting itself largely in higher deductibles, higher co-payments, and reduced benefits. There is also a growing array of CDHP products being offered by all the national health insurance carriers, Blue Cross Plans, Cigna, Aetna, United HealthCare and Well Point. In addition, there is an expanding industry of niche start-up companies - early entrants such as Lemenos and Definity. These two have recently been acquired by Well Point and United Health Care respectively. In the earlier stages, CDHP was mainly focused on cost management and cost shifting. In the longer term, the goal of CDHP is to engage the consumer in a more educated process of benefits purchasing, provider selection, and management of consumption of services. One can hypothesize that such an engagement can be at least partially achieved using Information and Communications Technology (ICT).

The growing trend in the increased offering of CDHP products has significant implications to healthcare providers. With the growth of these plans, the burden 
of healthcare falls more on the consumer to pay for higher out-of-pocket-costs. Typically, every time a consumer spends a dollar on physicians' services, only 20 cents are paid out of pocket; the remainder is paid by health plan, employer and government referred to as the third party. From a purely economic perspective, then, user's incentive is to consume these services until their value to them is only 20 cents on the dollar. Additionally, millions of consumers such as Medicaid enrollees, Medicare enrollees who have medi-gap insurance, and people who get free care from community health centers and hospital emergency rooms, do not even pay the 20 cents. While employers are grappling with the increasing health care costs, there continues to be a shift to consumers to bear the responsibility. The shift is expected to accelerate because of the government encouragement to enroll as many as 25 percent in high deductible health plans by the end of the decade [4].

Early evidence of these CDHP products assisting consumers to reduce costs in most studies is questionable. The results thus far do suggest that CDHP could reduce the cost and spending on healthcare. The other side of CDHP raises concerns about whether reductions in cost are sustainable in the long run. Another concern is whether consumers have the information and resources to begin making rational decisions about their healthcare situation. Critics have also raised the issues of whether the consumers will compromise on the appropriate utilization of services or neglect to use the available information about quality [5].

The growth of these products makes the consumers bear a substantial portion of healthcare cost. The RAND Health Insurance Experiment [HIE] indicates that cost sharing (paying out of pocket expenditures by consumer) reduces costs by lowering healthcare utilization, but could also lead to some undesirable consequences. Cost sharing reduced the percentage of low-income adults who were associated with higher blood pressure control "highly effective care for acute conditions" by 39 percent. There were reports of less reliable use of preventive care measures such as Pep smears. However, advocates believe that shifting part of the increased cost to the consumer will turn consumers into informed consumers who will exert pressure on healthcare providers to improve the efficiency, quality of care and reduce medical errors [6].

Most economists believe that increasing the price of an item will decrease demand for the item. Health care is no different from any other good. If you increase the co-payment or coinsurance rate, people will consume fewer medical services. The RAND HIE demonstrated that higher coinsurance rates discourage medical care consumption. [6]

In general, most studies, starting with the RAND HIE study, conclude that increasing the costs (co-payments and deductibles) of health care to the patient reduces the consumption of health care, but reduces the consumption of both appropriate and inappropriate care, and the reduction is greater for low-income patients. For example, Newhouse, in summarizing the RAND study, reported that visits to physicians and hospitals decline with higher cost sharing "although for low income families such cutbacks reduced their use of beneficial as well as unnecessary services and was estimated to have increased rates of death from preventable illness" [6].

Health savings accounts (HSAs) have been a major point of contention for health care reformers. Supporters claim that HSAs can reduce health care costs by decreasing the moral hazard problem inherent when third parties-such as insurance companies or the government-pay for medical services. Opponents 
claim that HSAs will attract rich and healthy individuals, leaving only poor or sick individuals in the 'regular' insurance pool [7].

There has been an increase in research analyzing the actual cost and quality impact of CDHP, this new form of health care has been increasing. Researchers at the Carlson School of Management at the University of Minnesota (Stephen $T$. Parente), Harvard University (Meredith Rosenthal), University of Illinois at Chicago (Anthony LoSasso) and RAND HIE have examined results of these plans. The large health plans, Aetna, WellPoint, Humana and UnitedHealth Group have all provided their own independent analyses as well. Other countries with experience in this type of health plans include: China, Taiwan, Singapore and South Africa. "Research conducted by the Galen Institute has found that consumers around the world who operate under CDHP products are value conscious when it came to healthcare and more focused on preventive care" [6].

Critics of CDHP argue that the healthcare system will only burden consumers with more expenses because free-market variables can never exist in healthcare due to lack of pricing transparency, that is clearly established pricing. "Despite the theory (as expressed in the Economic Report of the President) that health insurance with higher deductibles will lead to consumers shopping around for health services (based on price and quality), the reality of inadequate information in the marketplace about health care quality and prices precludes the workability of a 'consumer-choice' type of model" according to Gail Shearer, director of health policy analysis for Consumers Union, to the Joint Economic Committee of the U.S. Congress in February of 2004 [8].

Do consumers get adequate healthcare quality and pricing information in the marketplace? The current environment makes it difficult for consumers to be well informed. Consumers are inundated with enormous amount of medical information from the Internet, medical journals, television and newspaper advertisements, websites, friends and relatives, to the extent that there is information overload. Consumers are becoming more knowledgeable and seek clinical relevant information while demanding prompt responses from the medical profession [9]. In such a situation, can consumers be capable of assuming the responsibility of making rational health care decisions? On the other hand, will the health of these consumers suffer because they elect not to seek care or adhere to medication regimens? For a long time, consumers were only responsible for a minimum payment and the Government, Employer or Health Plan paid the rest. Now, the informed consumer is expected to take charge and bring about healthcare efficiencies.

\section{Information Asymmetry in Health Care}

Kenneth Arrow in his seminal article recognized that Healthcare is characterized by extremely high level of uncertainty and the consumers' uncertainty about the consequences of purchasing healthcare services. Patients as consumers have this inherent inability to fully understand the effectiveness of medical treatments, and are about the remedy for their sickness or relief of pain. This makes it very difficult for consumers to learn and evaluate the quality of healthcare services. Arrow also recognized that under conditions of uncertainty, correct information becomes a valuable commodity. He further recognized that information's 
"elusive character" limits the marketability of both the demand and supply sides of the market. There are limits on consumers' ability to acquire information and consumers' potential to process information. This is more pronounced specifically for cases of acute illnesses where the limits on acquiring information are uncertain due to inexperience. Furthermore, consumers who are confronted with new illnesses face a very challenging dilemma as they have limited time to research and collect information. The effectiveness of many medical treatments depends on minimizing the time between the onset of illness and the start of the treatment [10].

Arrow saw the unique asymmetric nature of the information in medical markets. Arrow discusses that some market participants will be better informed than others will. "Like other commodities, it has a cost of production and a cost of transmission, and so it is naturally not spread out over the entire population but concentrated among those who can profit most from it", asserts Arrow [11]. The average consumer will experience variation in costs and benefits due to differences in income, analytical abilities and various other factors. He concentrated on informational asymmetries between physicians and patients and comments that "Medical knowledge is so complicated, the information possessed by the physician as to the consequences and possibilities of treatment is necessarily very much greater than that of the patient, or at least so is believed by both parties. Further, both parties are aware of this informational inequality, and their relation is colored in knowledge" [11].

With the growth of the Internet, various new sources provide the potential for a metamorphosis of physician-dependent patients into better informed consumers. The Internet will never replace physicians as patients' primary source of information on the efficacy of various medical treatments. Even for the most educated consumer with all the relevant medical information, there are barriers to consumers' abilities to process it and to make choices between treatments independently from their respective physicians. Patients tend to rely on guidance from their physicians to understand medical factors in the context of their particular medical problems and to give these medical factors their proper diagnosis in the treatment protocols.

Accessing medical information from websites, medical journals, providers, health plans relatives, and friends has been the norm for many consumers. Sometimes, consumers can challenge the physician on treatment protocols and force the physicians to be responsive in a thoughtful way. Websites such as wipricepoint.com (Wisconsin) and nhpricepoint.com (New Hampshire) that have been initiated at the state levels can be resource to a certain extent in the charge (price) and some quality indicators. With all the information available, the consumer is often overwhelmed as to what is the right treatment.

Traditional approaches for managing healthcare prices are inadequate in an environment of competition. Cognizant of the role the physician plays, the development of performance based healthcare is still at its embryonic stage according to M. Millenson [9]. With the advent of CDHP, the shift of cost to the patient is inevitable. The consumer will be more judicious with shopping for health care services related to cost and quality. Therefore, information symmetry becomes highly relevant. In a free market situation where the doctor is primarily motivated by the profit motive, the possibility exists for physicians to exploit patients by advising more treatment to be purchased than is necessary, a supplier induced demand. Traditionally, physician's behavior is controlled by a professional code of ethics and a system of licensure. In other words, people 
can only work as physicians provided they are licensed and this in turn depends upon their acceptance of a code which makes the obligations of being an agent explicit or as Kenneth Arrow puts it that "the control that is exercised ordinarily by informed buyers is replaced by internalized values" [11].

So, if physicians behaved like some financial consultants or computer salesmen in the past and maximized profits without any restriction from a professional code, one would expect supplier induced demand to be a major problem. But, any system of licensure strong enough to provide the internalized values that Arrow discusses is also likely to give the medical profession power to limit the number of physicians operating. Thus, licensure and a professional code are in themselves also a source of market value. Arrows refers to this as "Supplier induced demand"[11].

Although, technology has given us more information than needed, sometimes it is very helpful, if not invaluable. There is good, solid data on the Internet that researchers can use with confidence. All of the available information can be helpful to general public with guidance. Searches for quality information have become considerably easier and quicker. In this way, information asymmetry can be reduced. Even if one thinks that one is unfamiliar with this phenomenon one usually goes through experiences in one's life when one was the victim of information asymmetry.

Here are a few examples that illustrates information asymmetry:

1. When a person is purchasing a new car, does the person feel comfortable and empowered when one starts to negotiate and haggle over price? Or, does the person feel out of control, not knowing exactly how much should one be paying for a car?

2. When a person is in their physician's office waiting to be called, one may have a list of concerns about which the person may know next to nothing. The person is highly likely a victim of information asymmetry.

3. When a person is trying to find information on a stock or a particular industry, the person may go to one's investment adviser who, for some reason may try to change the person's focus to another stock or industry. The person is not sure what to do because one is challenged with information asymmetry

Jessie Gruman, who interviewed 200 patients and families about how they used scientific information after devastating medical diagnoses, said, "I fear that the trend toward consumer-driven health care will disproportionately damage the health of the less educated and less wealthy, and that the net effect on the nation's health has already proved negative" [12]. He concluded that most patients are unable to make critical decisions about their health care in the consumer-driven model. According to Gruman some people, called "monitors," track down detailed information, while other people, called "blunters," do not want information. In Gruman's study, he commented, one blunter -- a theoretical physicist, said that he would be "insulted" if someone read fifteen papers on theoretical physics and asked him to help design an experiment, he pays his doctor to explain his choices. A "monitor," a lawyer, applied her legal research skills but could not think clearly enough to decide. People go to Internet, become overwhelmed (or overloaded), or do not understand the significance of the information. "Most health information is bad news, is stressful, and makes decisions even more difficult" [12].

According to Robert Reischauer, president of the Urban Institute and Vice Chairman of the Medicare Payment Advisory Commission, accessible information on the quality, price, effectiveness and efficiency of health-care services and providers is developing rapidly, but is nowhere near the minimum 
standard assumed by well functioning CDHP [13]. For example, when one goes to the physician because of a particular set of symptoms, the physician may ask a number of questions that lead to a series of recommended tests whose results then determine an appropriate treatment regime. One could select the physician to visit on the basis of price and quality but there is no guarantee that the package of tests and treatments that resulted would be the lowest cost or highest quality. The costs of the really expensive treatments would be largely unaffected.

Despite criticism leveled at the new system in 2004 , a survey by the Blue Cross and Blue Shield Association found widespread satisfaction among HSA customers. "The survey found that HSA products are on par with non consumerdirected health plans (CDHPs) with 85 percent of respondents saying the product meets or exceeds expectations for controlling healthcare expenditures. The survey also revealed that 47 percent of those consumers with HSAs experienced an increase in satisfaction over the previous year, while only 27 percent of consumers with traditional health plans showed an increase in satisfaction" [7].

The proponents of CDHP, like former House Speaker Newt Gingrich, have pointed to the rise of the Internet and online comparative shopping health services as one reason they believe the CDHP model is viable. Key to CDHP's success will be the quality (and quantity) dissemination of information about health products and services [14].

In 2006, a few of the technology firms capitalized on what they believe will be a new market for comparative healthcare shopping with the growth of CDHP plans and with the goal of leveraging the Internet to enhance price transparency and quality information dissemination in the healthcare market [15].

If information asymmetry can be minimized, it will help lower prices and lead to price transparency. The use of ICT becomes critical to operationalize such a system. ICT is already heralded as an effective way to improve quality both clinical and administrative areas and save money in healthcare. Unfortunately, evaluating return on investment (ROI) for ICT remains challenging. Until a market mechanism is developed to allow all stakeholders to equitably share the benefits of ICT adoption, broad-scale adoption will not come to fruition [1].

Each of the stakeholders of healthcare delivery is an independent entity. Physician offices are completely separate from the local emergency room or hospital. The same consumer may have laboratory or imaging tests performed in multiple venues such as several physicians' offices, more than one hospital, and independent laboratories or imaging facilities. Currently, none of these systems are linked with others. ICT can assist in improving price transparency, minimize information asymmetry, reduce the price of healthcare and bring efficiency in the market information. ICT can have a tremendous impact on improving accessibility of integrated data from medical claims and providers. The goal is to let consumers of healthcare analyze comparative prices based on quality and price information related to diagnoses and treatment with improving quality. ICT can play a more significant role in health care today and in the future. We can alter the delivery of healthcare, leveraging ICT to give scalable price efficiencies and improve the dissemination of information. This can reduce information asymmetry to the consumers and justify the true price of service rendered. ICT could have significant impact on improving quality and accessibility of health care in the US while controlling the price of health spending using health information technology [16].

Strategically, ICT can help remove healthcare information asymmetry between all stakeholders in the healthcare industry and, especially between 
ultimate consumer and the rest. ICT makes it possible to connect and share the critical information necessary in making efficient operation of healthcare service chain. ICT will allow aggregation, consolidation, summation and differentiation of prices relating to service procedures and value of components services, and display information to consumers to make effective selection of services, providers and physicians. ICT will also allow this interchange and delivery of this information to consumers in easy user-friendly methods using web infrastructure thus empowering all services users. ICT can also empower the health care consumers to keep an ongoing dialog and report card on insurers, providers, and physicians with regard to prices and quality of their services [16].

\section{Comments and Conclusions}

In the above discussion, it is made clear that CDHP is here to stay. It is also true that variety of models are being tried to really put consumers in the driver seat in deciding on the true value of the healthcare services. Implicitly and explicitly several studies have shown that although it is difficult to clearly prove that CDHP will drive the healthcare costs down and healthcare market more efficient, in the long run they are expected to rein in the healthcare costs.

There are several antecedents that are necessary in making such a health care market happen.

One: The consumers of healthcare should be well informed about all the choices they have before they subscribe to any of health care services.

Two: The information consumers are seeking before or at the Point Of Service (POS) is readily available to them ubiquitously.

Three: The information is provided to the consumers regarding all relevant health care stakeholders, and is properly communicated to them through proper understandable metrics (an average individual can understand).

Four: The consumers are educated (or have an opportunity to educate themselves) about the healthcare and health care quality metrics in their decision making process.

Five: The consumers are educated about the role of different stakeholders and their role in value creation process.

Six: The consumers have a trusted place (typically on Internet) where they can post their opinions about the services they have used. These feedbacks then will become an integral part of overall quality metrics of each of the stakeholders.

One can hypothesize based on the above suppositions that the reduction in the information asymmetry among healthcare stakeholders will make the healthcare market efficient. The critical importance of ICT use as a driver in creating such information and disseminating it to the POS and simultaneously encouraging adoption and diffusion of such technology among all the stakeholders cannot be overemphasized. However, the dark side of such a system if allowed to unfold in unplanned, uncontrolled and anarchic fashion can at times be to the detriment of the very purpose it was intended, in this case information overload can become one of the negative outcome of efforts to remove information asymmetry. Issues relating information overload is outside the scope this paper and needs to be discussed separately. 


\section{References:}

1. B. Middleton, "Achieving U.S. Health Information Technology Adoption: The Need For A Third Hand", Health Affairs, September/October 2005, Vol 25, pp.1269-1272.

2. S.M. Retchin, MD, MSPH, "Overcoming Information Asymmetry in Consumer Directed Health Plans", The American Journal of Managed Care, Vol 13, No 4, April 2007.

3. Cardon and Showalter, "Insurance Choice And Tax-Preferred Health Savings Accounts", Journal of Health Economics, 2007, Vol: 26(2), pp. 373-399.

4. T.H. Lee, M.D. and K. Zapert, Ph.D, "Do High-Deductible Health Plans Threaten Quality of Care?", New England Journal of Medicine 353, no 12, pp.1202-1204, September 22, 2005.

5. G. Wilensky, "Consumer-Driven Health Plans: Early Evidennce And Potential Impact On Hospitals", Health Affairs, January/February 2006 Vol: 25 pp.174185.

6. J.P. Newhouse, "Consumer-directed health plans and the RAND health insurance experiment", Health Affairs 2004; 23: pp.107-113 (Cited in BMJ $334: 238)$.

7. Healthy News Service, Blue Cross and Blue Shield Association Consumer Survey Shows High Rate of Satisfaction With HSAs Cites Increased Reliance On Decision Support Tools, October 10, 2005.

8. http://www.consumersunion.org/pub/0225JECTestimonyNoSummary.pdf

9. M. Millenson, "Medical Informatics Internet, Performance-based Healthcare -The Coming Transformation of Medical Practice", Business Briefing: Next Generation Healthcare, October 2000, pp.28-31.

10. D.Haas-Wilson, Uncertain Times, Kenneth Arrow and the Changing Economics of Health Care, 2003 Duke University Press, Arrow and the Information Market failure in Health Care: The Changing Content and Sources, pp.169-180.

11. K. J. Arrow, "Uncertainty and the Welfare Economics of Medical Care", American Economic Review 53, pp.941-973, 1963.

12. J. Gruman, PhD, Executive Director, Center for the Advancement of Health, Keynote Address, Transforming Consumer Decision Making, Promises and Pitfalls in Consumer Decision Making, Conference, Park City, Utah, 22 September 2005.

13. "Big Issues: Consumer Choice: Can It Cure The Nation's Health-Care Ills?" Wall Street Journal, December 13, 2005,

14. http://healthtransformation.net/news/cht_articles_and_op_eds/4375.cfm

15. http://online.wsj.com/article/SB $1148509362918 \overline{6} 236 \overline{2} . \mathrm{html}$

16. R.A. Burgelman, Dr. R. Pearl, MD and P.E. Meza, "Better Medicine Through Information Technology", Standford Graduate Schol of Business, October 24, 2004. 